\title{
Landscape structure affects dispersal in the greater white-toothed shrew: Inference between genetic and simulated ecological distances
}

\author{
Séverine Vuilleumier ${ }^{a, *}$, Pierre Fontanillas ${ }^{b, 1}$ \\ a Institute of Environmental Science and Technology, Swiss Federal Institute of Technology of Lausanne, CH-1015 Lausanne, Switzerland \\ $\mathrm{b}$ Department of Ecology and Evolution, University of Lausanne, $\mathrm{CH}-1015$ Lausanne, Switzerland
}

\section{A R T I C L E I N F O}

Article history:

Received 12 September 2005

Received in revised form

27 September 2006

Accepted 2 October 2006

Published on line 13 November 2006

Keywords:

Dispersal

Spatially explicit

Individual-based model

Simulation

Genetic differentiation

Ecological distance

Genetic distance

\begin{abstract}
A B S T R A C T
Dispersal is often viewed as a process on which the landscape has little effect. This is particularly apparent in populations' genetic and ecological studies, where isolation by distance is generally tested using a Euclidean distance between populations. However, landscapes can be richly textured mosaics of patches, associated with different qualities (e.g. different costs crossing patches) and different structures (shape, size and arrangement). An important challenge, therefore, is to determine if accounting for this additional complexity enriches our understanding of the dispersal processes.

In this study, we quantify the effect of landscape structure on dispersal distances between 15 populations of the greater white-toothed shrew (Crocidura russula) in a highly fragmented landscape in Switzerland. We use a spatially explicit individual-based model to simulate C. russula dispersal. This model is designed to account for movement behavior in heterogeneous landscapes. We explore the relationship between simulation results and genetic differentiation between actual subpopulations. Finally, we test if simulated dispersal distances are better predictors of genetic differentiation than traditional Euclidean distances.

The ecological distances measured by the model show a clear relationship with genetic differentiation between $C$. russula subpopulations. This relationship is stronger than the one obtained by the usual Euclidean distance.
\end{abstract}

(c) 2006 Elsevier B.V. All rights reserved.

\section{Introduction}

Dispersal is a key feature to understand many processes in population dynamics and genetics, behaviour ecology and conservation biology (Clobert et al., 1999; Stenseth and Lidicker, 1992). It has important demographic consequences such as stabilizing densities and maintaining viable metapopulations (Hanski, 1999; Hanski and Ovaskainen, 2000). Additionally, it is a vector of gene flow which may reduce the chances of inbreeding, enhance genetic diversity and improve evolutionary potential (Ralls et al., 1986; Wolff, 1994; Pursey and Wolf, 1996; Paradis et al., 2002).

In a landscape, landscape features and their spatial arrangement may guide or potentially inhibit the ability of species to disperse (Fahrig and Merriam, 1985; Turner, 1989; Peles et al., 1999). Because of this, there is certainly a complex relationship between dispersal success and geographical distance (Hansson, 1991). By modifying dispersal, landscape

\footnotetext{
* Corresponding author. Tel.: +41 21693 3767; fax: +41 216933913.

E-mail addresses: severine.vuilleumier@epfl.ch (S. Vuilleumier), pfontani@oeb.harvard.edu (P. Fontanillas).

1 Current address: Department of Organismic and Evolutionary Biology, Harvard University, 16 Divinity Avenue, Cambridge, MA 02138, United States. Tel.: +1 617496 5540/41 2169241 84; fax: +1 617496 5854/41 216924105. 0304-3800/\$ - see front matter @ 2006 Elsevier B.V. All rights reserved. doi:10.1016/j.ecolmodel.2006.10.002
} 
fragmentation and heterogeneity affects gene flow (Barton, 1992; Couvet, 2002).

Understanding how individual movement patterns are affected by the spatial structure of an environment is thus a key question (Wiens, 1995). The relationship between landscape heterogeneities and dispersal between populations can be estimated by three complementary approaches: field experiments (tracking, capture-recapture), genetic approaches (genetic differentiation) and modelling approaches (simulations).

Field experiments allow an estimate of rates of movement among discrete populations as well as estimates of dispersal parameters with capture-recapture data, mark-resight data, or tracking measures (Pollock et al., 1974; Brownie et al., 1993; Pradel, 1996; Bennetts et al., 2001). These methods require a large quantity of data, are difficult to obtain, and are time consuming and expensive (Hestbeck, 1982; Stenseth and Lidicker, 1992; Smith and Peacock, 1990; Koenig et al., 1996; Tischendorf, 1997; Wolff, 1999; Peacock et al., 1999). Other studies point out the failure of demographic methods to detect long-distance dispersal (Koenig et al., 1996).

As an alternative, the genetic approaches rely on quantification of genetic variation between populations (Barton, 1992; Slatkin, 1995; Mallet, 2001; Whitlock, 2001; Balloux and Goudet, 2002; Balloux and Lugon-Moulin, 2002). By assuming that dispersal occurs preferentially between nearby subpopulations, isolation by distance (IBD) models provide an estimation of genetic distances between populations in spatially explicit situations (Barton, 1992; Cockburn, 1992; Raymond and Rousset, 1995; Goudet, 1995; Belkhir et al., 2004). They have proved to be useful predictors of dispersal rates (Clobert et al., 1999; Berry et al., 2004). Other models provide estimation of dispersal rates between populations for example likelihood estimation (Kuhner et al., 1995; Beerli and Felsenstein, 1999; Bahlo and Griffiths, 2000; Beerli and Felsenstein, 2001) or assignment tests (Paetkau et al., 1997; Favre et al., 1997; Dawson and Belkhir, 2001; Cornuet et al., 1999; Piry et al., 2004). The genetic distance is our focus here, thus, we will consider methods related to isolation by distance (Raymond and Rousset, 1995; Goudet, 1995; Beerli and Felsenstein, 2001; Belkhir et al., 2004).

Animal dispersal models are useful to analyse complex dispersal as they allow the interactions of the individual with the landscape (Berger et al., 1999; Grimm et al., 1999; Hall and Halle, 1999). They have demonstrated their capacity to simulate animal movement and behaviour (Gustafson and Gardner, 1996; Blackwell, 1997; Carter and Finn, 1999; Farnsworth and Beecham, 1999; Moorcroft et al., 1999; Thulke et al., 1999; Tyre et al., 1999; Vuilleumier and Metzger, 2006). Additionally, they are a cost-effective approach to understanding dispersal dynamics (Koenig et al., 1996; Tischendorf, 1997; Wiegand et al., 1999; Pretsler et al., 2000; Tischendorf and Fahrig, 2000).

In this study, we use a spatially explicit individual-based model (Vuilleumier and Metzger, 2006; Vuilleumier and Perrin, 2006) to simulate the dispersal behaviour of the greater whitetoothed shrew, Crocidura russula. The model is used to simulate the dispersal of $C$. russula within a heterogeneous landscape, and to measure the distances between populations considering length of path used (the ecological distance). We characterize the relationship between ecological distance and genetic distance between $C$. russula populations and we ask if these ecological distances estimated by the model provide a useful enhancement to the traditional IBD model using Euclidian distances.

\subsection{C. russula ecology, study area and sampled populations}

C. russula is a small insectivorous mammal. This species is anthropophile in the central and western part of Europe due to its energetic needs (Ehinger et al., 2002). Therefore, the ecological distribution of $C$. russula is associated with inhabited areas, where they settle in gardens and hedges. In Switzerland C. russula rarely appear over $1000 \mathrm{~m}$, but are obligatorily anthropophilic above $600 \mathrm{~m}$, and are commonly seen at lower altitudes (400-600 m) (Genoud, 1995).

The study area is a highly fragmented landscape situated in western Switzerland (Fig. 1). It covers around $260 \mathrm{~km}^{2}$ in an altitude range of 390-930 $\mathrm{m}$. Lake Geneva (374 $\mathrm{m}$ ) and the Jura Mountains limit the distribution of the species in the study area. To avoid edge effect, the study area has been extended in the northeastern and the southwestern part, the other parts of the study area are limited by natural barriers to dispersal, the lake and the altitude (over $1000 \mathrm{~m}$ ).

In the study area, 15 subpopulations were sampled (Fig. 1). Sampling took place in 1999 and 2000 from June to August. One hundred and seventy individuals were recorded and were scored for seven autosomal microsatellite loci, for localization and trapping details see Ehinger et al. (2002) and Fontanillas et al. (2004).

\section{Genetic measurements}

In a metapopulation, genetic drift, mutation, selection and gene flow led to a specific pattern of genetic structure. In absence of selection, genetic and mutation should induce a differentiation among populations, unless migration causes a homogenetization. Several formulae have been proposed for estimating genetic distance (or similarity) between subpopulations, which vary in terms of their underlying genetic models or statistical models (see Takezaki and Nei (1996) for details). Among them the three following will be used for inferences from the simulation model:

(i) Manhattan metric $C_{M}$, which is a version of the Czekanowski's (1909) distance (Nei, 1987), where the difference between the frequency of the ith allele at the $j$ th locus in population $X$ and $Y$ is summed over the number of alleles at the jth locus and over the number of loci.

(ii) The pairwise $F_{\text {st }}$, which is one of the F-statistics (statistical tools used to describe the variance of allele frequencies by hierarchical partitioning (Wright, 1965)). This estimator measures the proportion of the total genetic variability due to genetic differentiation between populations. Therefore $F_{\text {st }}$ represents a measure of the Wahlund effect (Wahlund, 1928), which can be stated in terms of variance in allele frequency (Wright, 1943, 1965). Pairwise $F_{\text {st }}$ can be estimated and gives the genetic differentiation among populations (Cockerham and Weir, 1993; Weir, 1996). 


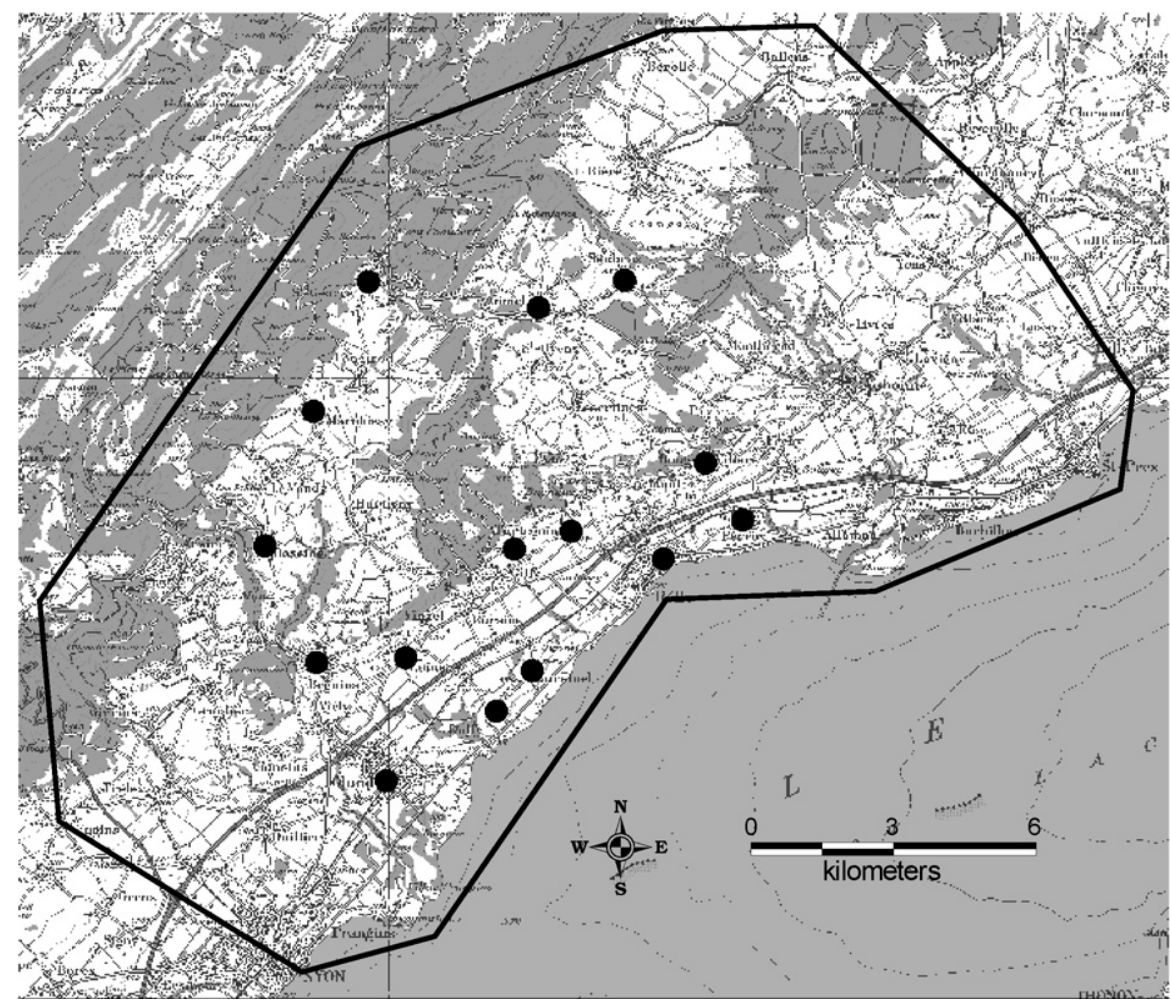

Fig. 1 - Study area and populations sampled (in black).

(iii) Nei et al.'s (1983) $D_{A}$ genetic distance where the squareroot of the product between the frequency of the ith allele at the jth locus in population $X$ and $Y$ is summed over the number of alleles at the jth locus and over the number of loci.

All these genetic distances provide a unique (symmetrical) estimation of the genetic differentiation between pairwise populations.

\section{Shrew dispersal modeling}

Shrew individual movements are simulated with a spatially explicit individual-based model. In this model, the landscape is explicitly represented under the form of an irregular patches network while behavioral traits of species are simulated with an individual-based model (see Vuilleumier and Metzger, 2006 for details of the model and Vuilleumier and Perrin, 2006 for theoretical applications).

In the spatially explicit landscape model, two main spatial entities are used: patches and frontiers. Patches represent homogenous areas of land use (fields, lakes or forest) and frontiers are linear landscape features (such as river shores, hedges and road sides). At the edge of the study area, we assume that boundaries are reflective.

The individual-based model simulates dispersal of individuals through the landscape (Vuilleumier and Metzger, 2006; Vuilleumier and Perrin, 2006). Dispersal is simulated as a successive selection of spatial entities at random, which create individual paths between two habitat patches. We assume that $C$. russula uses preferentially the linear structures across the landscape. This assumption is based on field experiences, showing that individuals are mostly trapped along linear features. The individuals move until they reach a different population or they exceed a maximum dispersal distance. We consider two scenarios: a "plausible scenario" in which the maximum dispersal distance is $15 \mathrm{~km}$; and a "maximum connectivity scenario" which will provide maximum connections between habitat patches and in which the maximum dispersal distance is $100 \mathrm{~km}$. We simulate the dispersal of 50,000 individuals from each subpopulation. This high number of replicates of individual movements through the landscape provides a stable response of the parameters (for details on sensitivity analysis on the model see Vuilleumier and Metzger, 2006).

The values extracted from the simulations are the distances of the path length travelled $D_{x y}$ for each successful disperser. They correspond to the distance an individual covers to reach a habitat patch $y$ from a habitat patch $x$. This measure captures the effect of landscape structure and heterogeneity in terms of distance. Over $n$ distances obtained by successful dispersers between two habitat patches, the median value is used and called "ecological distance". This value is asymmetric, i.e. $D_{x y}$ may differ from $D_{y x}$, and gives the intensity of the connection between two habitat patches in a particular direction. In the case that no dispersers from a patch $y$ reach a patch $x, D_{x y}$ is assumed to be the shortest distance of the path length joining patch $x$ and $y$ via a patch $k$, therefore $D_{x y}=D_{x k}+D_{k y}$. However, although one of the interests of using this individual based model is to provide asymmetric dispersal between local populations, we used symmetric ecological distances by averaging the two triangular half-matrices because 

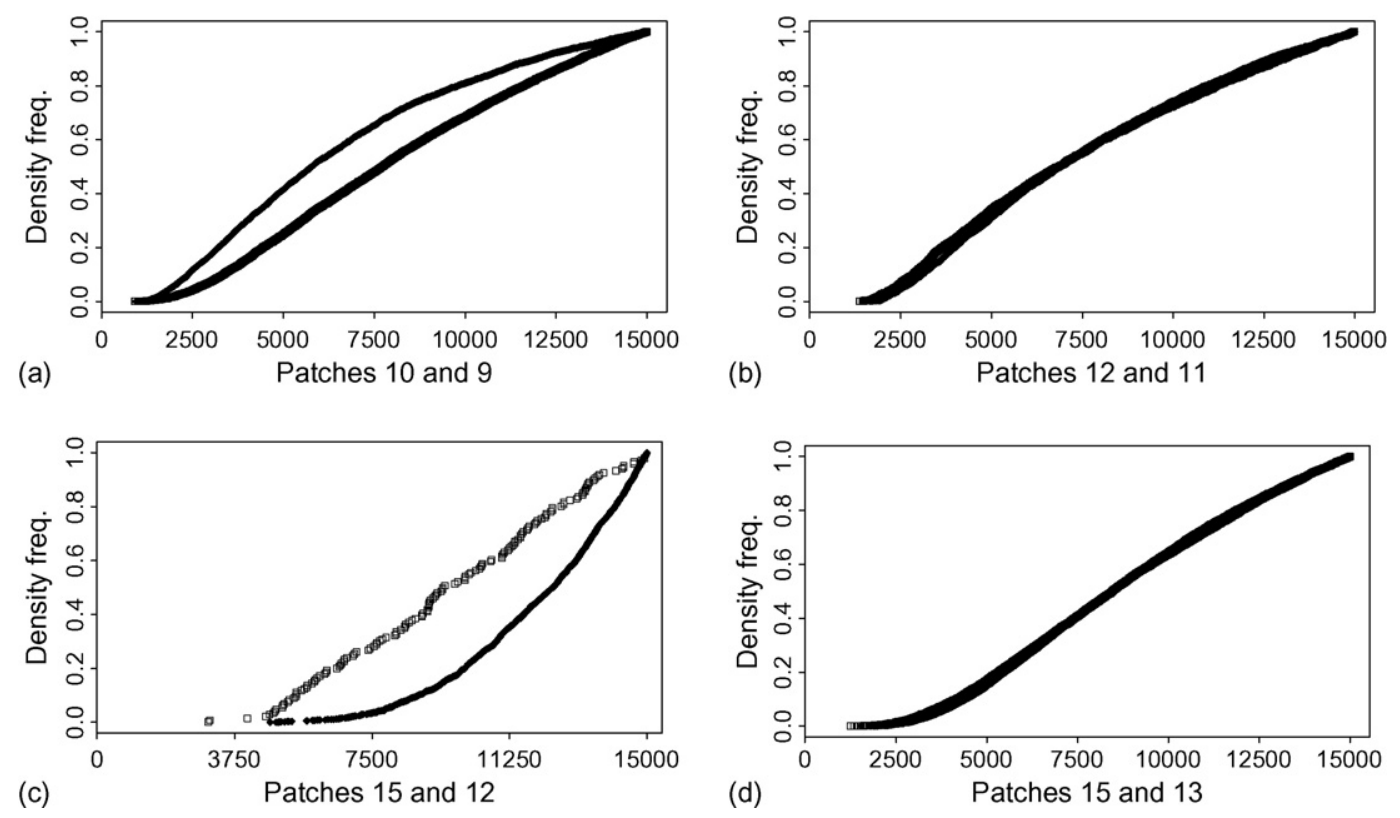

Fig. 2 - Ecological distances between habitat patches: in the figure are displayed the cumulative density frequencies of ecological distances between four pair of patches. In each case both directions are displayed, showing asymmetric dispersal in cases $a$ and $c$ and symmetric dispersal in cases b and d. Simulation sets consider dispersal distance up to $15,000 \mathrm{~m}$.

genetic distances are symmetric as well as the Euclidian distances between patches.

\section{Inferences between genetic and ecological distance}

Relationships between ecological distance and genetic distance was analysed with correlation tests. We used a classical non-parametric Mantel test (Manly, 1991; Legendre and Lapointe, 2004) to compare ecological and geographical distance matrices. The significance of the results was assessed by 9999 permutations of the matrices. Correlation results obtained between genetic and geographical distances were compared to correlations obtained with genetic and ecological distances using the Fisher $r$-to- $z$ transformation.

\section{Results}

Simulations of dispersers through the landscape provide distributions of ecological distances between pairs of patches (Fig. 2). Ecological distances are computed only when dispersers successfully reach a habitat patch. As suggested by the shape of the cumulative distributions of ecological distances presented in Fig. 2, no general distribution pattern has been found to describe all per pairs distributions of ecological distances (cluster analysis, available under request). The distribution of ecological distances between two patches can be similar (Fig. 2a and c) or different (Fig. 2b and d) depending on the environmental heterogeneity. In most of the cases, flow of individuals between patches is asymmetric.

The colonization probability is not only related to the distance between patches but to the environmental heterogene- ity (Fig. 3). Some distant patches, for example patches 2 and 8, 2 and 13, 3 and 4 or 11 and 9, are strongly connected even if their geographical positions do not provide such expectation. In the opposite, some connections between habitats, for example patches 4 and 5, 8 and 9, 6 and 7 or 7 and 12 show that even though these patches are geographically close; they are not well connected from an ecological point of view.

Correlations between simulated ecological distances, estimates of genetic distances and geographical distances for all pairs of populations are presented in Table 1. In this table, the value of the significance of incongruence probability never exceeds 0.0006 (Mantel test, $\chi^{2}, 9999$ permutation). Two sce-

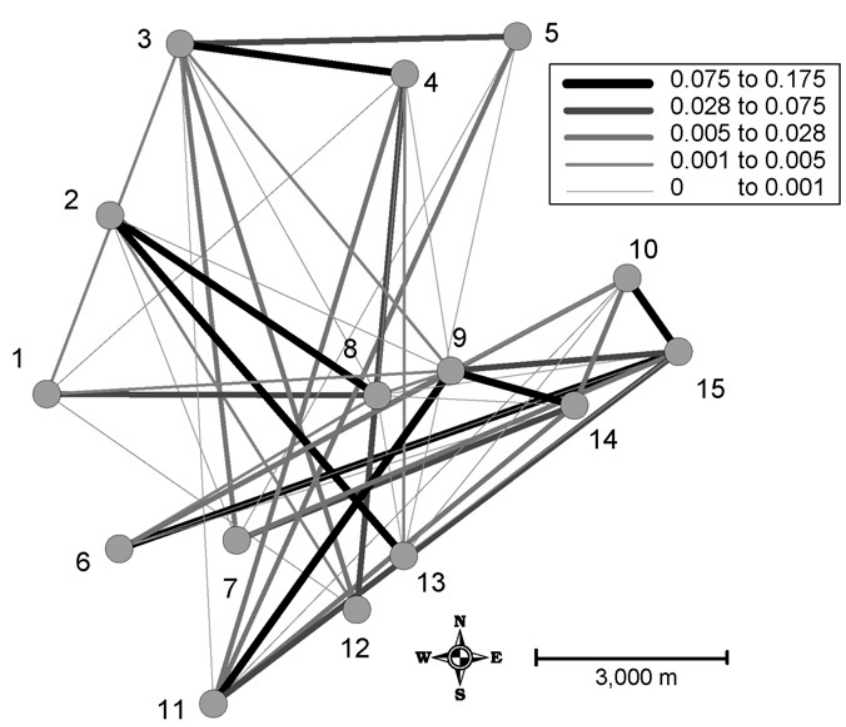

Fig. 3 - Colonization probability between habitat patches for the simulation set where dispersal is limited to $15,000 \mathrm{~m}$. 
Table 1 - Matrix of Mantel correlations based upon ranks (Spearman correlations) between three genetic distances, respectively the Manhattan metric, the pairwise $F_{\text {st }}$ and the Nei et al.'s (1983) and ecological distances produced by simulation where dispersal is limited to 15 and $100 \mathrm{~km}$ and geographical distances

\begin{tabular}{lccc} 
Genetic distances & Geographical distance & \multicolumn{2}{c}{ Ecological distance } \\
\cline { 3 - 3 } & & $15 \mathrm{~km}$ & $100 \mathrm{~km}$ \\
\hline Manhattan & 0.55 & 0.60 & 0.64 \\
$F_{\text {st }}$ & 0.41 & 0.50 & 0.52 \\
Nei & 0.59 & 0.67 & 0.69 \\
\hline \multicolumn{2}{l}{ Significance of incongruence probability never exceeds 0.0006 (Mantel test, $\chi^{2}, 9999$ permutation). } \\
\hline
\end{tabular}

narios of simulated ecological distances between populations are presented, the "plausible scenario", with maximum dispersal distance set to $15 \mathrm{~km}$, and the "maximum connectivity scenario" with maximum dispersal distance set to $100 \mathrm{~km}$. The correlation values between genetic distances and maximum connectivity scenario are higher than those using geographical distance, reaching $0.64,0.52$ and 0.69 , respectively for the Manhattan metric, the pairwise $F_{\text {st }}$ and the Nei et al.'s (1983) genetic distance (Fisher $r$-to- $z$ transformation, $p$-values: Manhattan measure $=0.071, F_{\text {st }}=0.069$, Nei et al.'s (1983) genetic distance $=0.036$ ).

The "plausible scenarios" show no significant difference from correlations obtained with straight geographical distance (Fisher $r$-to- $z$ transformation, $p$-values: Manhattan measure $=0.32, F_{\text {st }}=0.14$, Nei et al.'s $(1983)$ genetic distance $=0.31$ ). The effect of distance and landscape structure is in our case better explained by Nei et al.'s genetic distance (1983), it provided systematically better correlation compared to other genetic distance measures we have used.

\section{Discussion}

Results presented here show that genetic differentiation of $C$. russula between habitat patches is better correlated to one ecological distance generated by the model than to geographical distance. Landscape structure and heterogeneity act on individual exchanges between $C$. russula populations.

We obtain better correlations with genetic distance when we assume a dispersal distance limited to $100 \mathrm{~km}$ - the "maximum connectivity scenario" - than when the dispersal is limited to $15 \mathrm{~km}$, "the plausible scenario". Given that the latter scenario was introduced to emulate realistic dispersal distances for the species, the model appears not to reproduce an individual dispersal process. Rather, the model seems to estimate the connectivity between populations.

While the combination of fine-scale behaviour responses and broad-level movement patterns present an improvement over existing approaches to analyse factors affecting genetic differentiation among populations, there are some limitations inherent in the approach. These limitations are related to assumptions underlying both genetic estimates and dispersal.

In dispersal modelling, "dispersal" means one-way movements of individuals away from their habitat patches and with no return (Stenseth and Lidicker, 1992). Therefore, animal dispersal differs from gene dispersal (Hanski, 1999), which requires subsequent incorporation of genes into a new generation by reproduction (Endler, 1977; Barton, 1992). Therefore modelling gene dispersal must account for other aspects linked to gene incorporation in the population such as population dynamics, sociality, or fitness (Hestbeck, 1982; Smith and Peacock, 1990; Lidicker and Stenseth, 1992; Koenig et al., 1996; Lima and Zollner, 1996; Wolff, 1997, 1999).

Finally, time scale is not accounted for explicitly. Indeed, the rapid landscape change may result in different patterns of gene flow among populations over time, genetic differentiations between populations might have occurred at a time when the landscape arrangement was different.

Spatially explicit modelling allows simulation of individual dispersal with movement behaviour and species interactions with heterogeneous landscapes (Downing and Reed, 1996; Beecham and Farnsworth, 1998; Lorek and Sonnenschein, 1999). It provides a quantification of dispersal processes according to landscape structures (Gustafson and Gardner, 1996; With et al., 1997; Farnsworth and Beecham, 1999; Thulke et al., 1999; Tyre et al., 1999; With et al., 1999; Bennetts et al., 2001; Berggren et al., 2001; Gardner and Gustafson, 2004).

As shown in this study, the use of individual-based model to simulate dispersal in heterogeneous landscape provides a estimation of asymmetric flow of individuals between habitat patches, such estimation could be of interest as asymmetric dispersal and colonisation can affect metapopulation dynamics and evolution (Saether et al., 1999; Whitlock and Mccauley, 1999; Kawecki and Holt, 2002; Vuilleumier and Possingham, 2006) and most of actual models assume symmetric dispersal (Dias, 1996; Hanski, 1999; Whitlock and Mccauley, 1999). Indeed, asymmetry has been considered in evolutionary and genetic fields but seldom considered in metapopulation dynamics and conservation biology (Morris, 1991; Dias, 1996; Case and Taper, 2000; Kawecki and Holt, 2002). In such literature, dispersal is tacitly assumed symmetric, even if dramatic consequences are predicted when dispersal appears to be asymmetric (Vuilleumier and Possingham, 2006).

The parameterisation of such models is a crucial issue (Koenig et al., 1996; Tischendorf, 1997). Estimation of dispersal can be performed by genetic and demographic methods. Some studies conclude on agreement (Eldridge et al., 2001; Maudet et al., 2002; Berry et al., 2004) but many have indicated discrepancies, (e.g. Hastings and Harrison, 1994; Slatkin, 1994; Ward et al., 1994; Koenig et al., 1996, for reviews). Even if, due to the complexity of the processes involved, the genetic measures are not yet completely adapted and unified, we believe that they offer a new field of investigation for disper- 
sal model simulation parameterisation. Our application with simple modelling assumptions shows that the genetic differentiation among populations can be related to landscape structure.

\section{Acknowledgement}

We thank Dr. Grant Hamilton for its comments on previous versions of the manuscript.

\section{REFERENCES}

Bahlo, M., Griffiths, R.C., 2000. Inference from gene trees in a subdivided population. Theor. Popul. Biol. 57, 79-95.

Balloux, F., Goudet, J., 2002. Statistical properties of population differentiation estimators under stepwise mutation in a finite island model. Mol. Ecol. 11, 771-783.

Balloux, F., Lugon-Moulin, N., 2002. The estimation of population differentiation with microsatellite markers. Mol. Ecol. 11, 155-165.

Barton, N.H., 1992. The genetic consequences of dispersal. In: Stenseth, N.C., Lidicker, W.Z.J. (Eds.), Animal Dispersal: Small Mammals as a Model. Chapman \& Hall, London, pp. 37-59.

Beecham, J.A., Farnsworth, K.D., 1998. Animal foraging from an individual perspective: an object oriented model. Ecol. Model. 113, 141-156.

Beerli, P., Felsenstein, J., 1999. Maximum likelihood estimation of a migration rate and effective population numbers in two populations using a coalescent approach. Genetics 152, 763-773.

Beerli, P., Felsenstein, J., 2001. Maximum likelihood estimation of a migration matrix and effective population sizes in $n$ subpopulations by using a coalescent approach. PNAS 98, 4563-4568.

Belkhir, K., Borsa, P., Chikhi, L., Raufaste, N., Bonhomme, F., 1996-2004. GENETIX 4.05, logiciel sous Windows TM pour la génétique des populations. Laboratoire Génome, Populations, Interactions, CNRS UMR 5171, Université de Montpellier II, Montpellier (France).

Bennetts, R.E., Nichols, J.D., Lebreton, J.-D., Pradel, R., Hines, J.E., Kitchens, W.M., 2001. Methods for estimating dispersal probabilities and related parameters using marked animals. In: Clobert, J., Danchin, E., Dhondt, A.A., Nichols, J.D. (Eds.), Dispersal, Oxford, 3-17.

Berger, U., Wagner, G., Wolff, W.F., 1999. Virtual biologist observes virtual grasshoppers: an assessment of different mobility parameters for the analysis of movement patterns. Ecol. Model. 115, 119-127.

Berggren, A., Carlson, A., Kindvall, O., 2001. The effect of landscape composition on colonization success, growth rate and dispersal in introduced bush-crickets Metrioptera roeseli. J. Anim. Ecol. 70, 663-670.

Berry, O., Tocher, M.D., Sarre, S.D., 2004. Can assignment tests measure dispersal? Mol. Ecol. 13, 551-561.

Blackwell, P.G., 1997. Random diffusion models for animal movement. Ecol. Model. 100, 87-102.

Brownie, C., Hines, J.E., Nichols, J.D., Pollock, K.H., Hestbeck, J.B., 1993. Capture-recapture studies for multiple strata including non-Markovian transition probabilities. Biometrics 49 , 1173-1187.

Carter, J., Finn, J.T., 1999. MOAB: a spatially explicit, individual-based expert system for creating animal foraging models. Ecol. Model. 119, 29-41.
Case, T.J., Taper, M.L., 2000. Interspecific competition, environmental gradients, gene flow, and the coevolution of species' borders. Am. Nat. 155, 583-605.

Clobert, J., Piry, S., Luikart, G., Estoup, A., Solignac, M., 1999. New methods employing multilocus genetotypes to select or exclude populations as origins of individuals. Genetics 153 , 189-2000.

Cockburn, A., 1992. Habitat heterogeneity and dispersal: environmental and genetic patchiness. In: Stenseth, N.C., Lidicker, W.Z.J. (Eds.), Animal Dispersal: Small Mammals as a Model. Chapman \& Hall, London, pp. 65-95.

Cockerham, C.C., Weir, B.S., 1993. Estimation of gene flow from F-statistics. Evolution 47, 855-863.

Cornuet, J.M., Piry, S., Luikart, G., Estoup, A., Solignac, M., 1999. New methods employing multilocus genotypes to select or exclude populations as origins of individuals. Genetics 153, 1989-2000.

Couvet, D., 2002. Deleterious effects of restricted gene flow in fragmented populations. Cons. Biol. 16, 369-376.

Czekanowski, J., 1909. Zur Diferenzialdiagnose der Neandertalgruppe. Bl. dtsch. Ges. Antrop. Ethn. Urgesch., Braunschweig, 40.

Dawson, K.J., Belkhir, K., 2001. A bayesian approach to the identification of panmictic populations and the assignment of individuals. Gene. Res. 78, 59-77.

Dias, P.C., 1996. Sources and sinks in population biology. Tree 11, 327-330

Downing, K., Reed, M., 1996. Object-oriented migration modelling for biological impact assessment. Ecol. Model. 93, 203-219.

Ehinger, M., Fontanillas, P., Petit, E., Perrin, N., 2002. Mitochondrial DNA variation along an altitudinal gradient in the greather white-tooted shrew, Crocidura russula. Mol. Ecol. 11, 939-945.

Eldridge, M.D.B., Kinnear, J.E., Onus, M.L., 2001. Source populations of dispersing rock-wallabies (Petrogale tateralis) identified by assignment tests on multilocus genotypic data. Mol. Ecol. 10, 2867-2876.

Endler, J.A., 1977. Geographic Variation, Speciation, and Clines. Princeton University Press, Princeton, New Jersey.

Fahrig, L., Merriam, G., 1985. Habitat patch connectivity and population survival. Ecology 66, 1762-1768.

Farnsworth, K.D., Beecham, J.A., 1999. How do grazers achieve their distribution? A continuum of models from random diffusion to the ideal free distribution using biased random walks. Am. Nat. 153, 509-526.

Favre, F., Balloux, F., Goudet, J., Perrin, N., 1997. Female-biased dispersal in the monogamous mammal Crocidura russula: evidence from field data and microsatellite patterns. Proc. $R$ Soc. B 264, 127-132.

Fontanillas, P., Petit, E., Perrin, N., 2004. Estimating sex-specific dispersal rates with autosomal markers in hierarchically-structured populations. Evolution 58, 2369-2374

Gardner, R.H., Gustafson, E.J., 2004. Simulating dispersal of reintroduces species within heterogeneous landscapes. Ecol. Model. 171, 339-358.

Genoud, M., 1995. Crocidure russula. In: Hausser, J. (Ed.), Mammifères de la Suisse. Birkhäuser-Verlag, Basel, pp. 49-53.

Goudet, J., 1995. FSTAT (vers. 1.2): a computer program to calculate F-statistics. J. Heredity 86, 485-486.

Grimm, V., Wyszomirski, T., Aikman, D., Uchmanski, J., 1999. Individual-based modelling and ecological theory: synthesis of a workshop. Ecol. Model. 115, 275-282.

Gustafson, E.J., Gardner, R.H., 1996. The effect of landscape heterogeneity on the probability of patch colonization. Ecology 77, 94-107.

Hall, S., Halle, B., 1999. Modelling activity synchronization in free-ranging microtine rodent. Ecol. Model. 115, 165-176. 
Hanski, I., 1999. Metapopulation Ecology. Oxford University Press, Oxford.

Hanski, I., Ovaskainen, O., 2000. The metapopulation capacity of a fragmented landscape. Nature 404, 755-758.

Hansson, L., 1991. Dispersal and connectivity in metapopulations. Biol. J. Lin. Soc. 42, 89-103.

Hastings, A., Harrison, S., 1994. Metapopulation dynamics and genetics. Rev. Ecol. Syst. 25, 167-188.

Hestbeck, J.B., 1982. Population regulation of cyclic mammals - the social fence hypothesis. Oikos 32, 157-163.

Kawecki, T.J., Holt, R.D., 2002. Evolutionary consequences of asymmetric dispersal rates. Am. Nat. 160, 333-347.

Koenig, W.D., Van Vuren, D., Hooge, P.N., 1996. Detectability, philoparty, and the distribution of dispersal distances in vertebrates. Tree 11, 514-517.

Kuhner, M.K., Yamato, J., Felsenstein, J., 1995. Estimating effective population size and mutation rate from sequence data using metropolis-hastings sampling. Genetics 140, 1421-1430.

Legendre, P., Lapointe, F.-J., 2004. Assessing the congruence among distance matrices: single malt Scotch whiskies revisited. Aust. NZ J. Stat. 46, 615-629.

Lidicker, W.Z.J., Stenseth, N.C., 1992. To disperse or not to disperse: who does it and why? In: Stenseth, N.C., Lidicker, W.Z.J. (Eds.), Animal Dispersal: Small Mammals as a Model. Chapman \& Hall, London, pp. 21-36.

Lima, S.L., Zollner, P.A., 1996. Towards a behavioral ecology of ecological landscapes. Tree 11, 131-135.

Lorek, H., Sonnenschein, M., 1999. Modelling and simulation software to support individual-based ecological modelling. Ecol. Model. 115, 199-216.

Mallet, J., 2001. Gene Flow. In: Woiwod, I.P., Reynolds, D.R., Thomas, C.D. (Eds.), Insect Movement: Mechanisms and Consequences: Proceedings of the Roy. Ent. Soc.'s 20th Symposium. CABI Publishing, Oxon, pp. 337-360.

Manly, B.F.J., 1991. Randomization and Monte Carlo Methods in Biology, 1st ed. Chapman \& Hall edition, London.

Maudet, C., Miller, C., Bassano, B., et al., 2002. Microsatellite DNA and recent statistical methods in wildlife conservation management: applications in Alpine ibex (Capra ibex (ibex)). Mol. Ecol. 11, 421-436.

Moorcroft, P.R., Lewis, M.A., Crabtree, R.-L., 1999. Home range analysis using a mechanistic home range model. Ecology 50 , 1656-1665.

Morris, R.W., 1991. On the evolutionary stability of dispersal to sink habitats. Am. Nat. 137, 907-911.

Nei, M., 1987. Molecular Evolution Genetics. Columbia University Press, New York.

Nei, M., Tajima, F., Tateno, Y., 1983. Accuracy of estimated phylogenetic trees from molecular data. II. Gene frequency data. J. Mol. Evol. 19, 153-170.

Paetkau, D., Waits, P.L., Clarkson, P.L., Craighead, L., Strobeck, C., 1997. An empirical evaluation of genetic distance statistics using microsatellite data from bear (Ursidae) populations. Genetics 147, 1943-1957.

Paradis, E., Baillie, S.R., Sutherland, W.J., 2002. Modeling large-scale dispersal distances. Ecol. Model. 151, 279-292.

Peles, J.D., Bowne, D.R., Barrett, G.W., 1999. Influence of landscape structure on movement patterns of small mammals. In: Barrett, G.W., Peles, J.D. (Eds.), Landscape Ecology of Small Mammals. Springer-Verlag, New York, pp. 41-62.

Piry, S., Alapetite, A., Cornuet, A., Paetkau, D., Baudouin, D., Estoup, D., 2004. GeneClass2: a software for genetic assignment and first generation migrants detection. J. Heredity 95, 536-539.

Pollock, K.H., Solomon, D.L., Robson, D.S., 1974. Tests for mortality and recuitement in a K-sample tag-recapture experiment. Biometrics 30, 77-87.
Pradel, R., 1996. Utilization of capture-mark-recapture for the study of recuitment and population growth rate. Biometrics 52, 703-709.

Pretsler, H.K., Brillinger, D.R., Ager, A.A., Kie, J.G., 2000. Analysis of animal movement using telemetry and GIS data. Proc. Am. Stat. As., 100-105.

Pursey, A.E., Wolf, M., 1996. Inbreeding avoidance in animals. Tree, 201-206.

Ralls, K., Harvey, P.H., Lyles, A.M., 1986. Inbreeding in natural populations of birds and mammals. In: Soule, M.E. (Ed.), Conservation Biology: Science of Diversity. Sinaur, Sunderland, MA, pp. 35-56.

Raymond, M., Rousset, F., 1995. An exact test for population differentiation. Evolution 49, 1280-1283.

Saether, B.-E., Engen, S., Lande, R., 1999. Finite metapopulation models with density-dependent migration and stochastic local dynamics. Proc. Biol. Sci. 266, 113-118.

Slatkin, M., 1994. Gene flow and population structure. In: Real, L.A. (Ed.), Ecological Genetics. Princeton University Press, Princeton, NJ, pp. 3-17.

Slatkin, M., 1995. A measure of population subdivision based on microsatellite allele frequencies. Gen. Soc. of Am. 139, 457-462.

Smith, A.T., Peacock, M.M., 1990. Conspecific attraction and the determination of metapopulation colonization rates. Cons. Biol. 4, 320-323.

Stenseth, N.C., Lidicker, W.Z.J., 1992. The study of dispersal: a conceptual guide. In: Stenseth, N.C., Lidicker, W.Z.J. (Eds.), Animal Dispersal: Small Mammals as a Model. Chapman \& Hall, London, pp. 1-20.

Takezaki, N., Nei, M., 1996. Genetic Distances and Reconstruction of Phylogenetic Trees from Microsatellite DNA. Gen. Soc. Am 144, 389-399.

Thulke, H.-H., Grimm, V., Müller, M.S., Staubach, C., Tischendorf, L., Wissel, C., Jeltsch, F., 1999. From pattern to practice: a scaling-down strategy for spatially explicit modelling illustrated by the spread and control of rabies. Ecol. Model. 117, 179-202.

Tischendorf, L., 1997. Modelling individual movements in heterogeneous landscapes: potentials of a new approach. Ecol. Model. 103, 33-42.

Tischendorf, L., Fahrig, L., 2000. How should we measure landscape connectivity? Land Ecol. 15, 633-641.

Turner, M.G., 1989. Landscape ecology: the effect of pattern on process. Annu. Rev. Ecol. Syst. 20, 171-197.

Tyre, A.J., Possingham, H., Lindenmayer, D., 1999. Modelling dispersal behaviour on a fractal landscape. Ecol. Model. 14, 103-113.

Vuilleumier, S., Metzger, R., 2006. Animal dispersal modelling: handling landscape features and related animal choices. Ecol. Model. 190 (1-2), 159-170.

Vuilleumier, S., Perrin, N., 2006. Effects of cognitives abilities on metapopulation connectivity. Oikos 113, 139-147.

Vuilleumier, S., Possingham, H.P., 2006. Does colonisation asymmetry matter in metapopulations? Proc. Biol. Sci. 273 (1594), 167-242.

Wahlund, S., 1928. Zusammensetzung von Populationen und Korrelationserscheinungen vom Standpunkt der Vererbungslehre ausbetrachtet. Hereditas 11, 65-106.

Wiegand, T., Moloney, K., Naves, J., Knauer, F., 1999. Finding the missing link between landscape structure and population dynamics: a spatially explicit perspective. Am. Nat. 154, 605-627.

Ward, R.D., Woodward, M., Skibinski, D.O.F., 1994. A comparaison of genetic diversity levels in marine, freshwater, and anadromous fishes. J. Fish Biol. 44, 213-232.

Weir, B.S., 1996. Genetic Data Analysis. Sinauer, Sunderland, MA. 
Whitlock, M.C., 2001. Dispersal and the genetic properties of metapopulations. In: Clobert, J., Danchin, E., Dhondt, A.A., Nichols, J.D. (Eds.), Dispersal, Oxford, p. 452.

Whitlock, M.C., Mccauley, D.E., 1999. Indirect measures of gene flow and migration: $\mathrm{FST} \neq 1 /(4 \mathrm{Nm}+1)$. Heredity 82 , 117-125.

Wiens, J.A., 1995. Landscape mosaic and ecological theory. In: Hansson, L.L., Fahrig, Merriam, G. (Eds.), Mosaic Landscapes and Ecological Processes. Chapman and Hall, London, pp. 1-26.

With, K.A., Gardner, R.H., Turner, M.G., 1997. Landscape connectivity and population distributions in heterogeneous environments. Oikos 78, 151-169.
With, K.A., Cadaret, S.J., Davis, C., 1999. Movement responses to patch structure in experimental fractal landscapes. Ecology 80, 1340-1353.

Wolff, J.O., 1994. More on juvenile dispersal in mammals. Oikos $71,349-352$.

Wolff, J.O., 1997. Population regulation in mammals: An evolutionary perspective. J. Anim. Ecol. 66, 1-13.

Wolff, J.O., 1999. Behavioral Model Systems. In: Barrett, G.W., Peles, J.D. (Eds.), Landscape Ecology of Small Mammals. Springer-Verlag, New York, pp. 11-40.

Wright, S., 1943. Isolation by distance. Genetics, 114-138.

Wright, S., 1965. The interpretation of population structure by F-statistics with special regard to systems of mating. Evolution 19, 395-420. 